\title{
Effects of Acrylic Restorations on the Periodontium of Monkeys
}

\author{
CARLOS E. NASJLETI, WALTER A. CASTELLI, and BENJAMIN E. KELLER \\ Veterans Administration Hospital and the University of Michigan, \\ Ann Arbor, Michigan 48105, USA
}

Replanted teeth that had an acrylic restoration in the middle third of their roots were studied from three days to six months after grafting. The study revealed that the acrylic obturator elicited epithelial proliferation, fibrous encapsulation, moderate chronic inflammation, and adjacent alveolar bone loss.

Data dealing with successful or unsuccessful acrylic tooth implants have accumulated gradually during the past 20 years. Flohr ${ }^{1}$ studied plastic material as a possible substitute for natural teeth by placing screw-type acrylic roots into surgically created alveolar sockets. He reported that normal connective tissue formed against the acrylic, and only minimal infiltration occurred. Hodosh, et $\mathrm{al}^{2-4}$ reported a high degree of success with acrylic implants in man, baboons, and dogs. Success was measured by the firmness and stability of the implants, by their ability to stand up under the stress of mastication, and by the absence of gross gingival and periodontal diseases. Brown, Neff, and Tylenda ${ }^{5}$ reported encouraging results in a preliminary study of acrylic tooth implants in monkeys.

On the other hand, Waerhaug and Zander ${ }^{6}$ demonstrated that acrylic resin implants exerted little or no irritation on hard and soft tissues, but concluded that the life of the acrylic implant is limited and that it is probably of no practical value. Narang and Wells $^{7}$ reported that efforts to achieve longterm maintenance of acrylic tooth implants have achieved only limited success. Failures were characterized by gingival inflammation, alveolar bone loss, and excessive mobility of the acrylic tooth implants. In spite of careful splinting, Iwaschenko ${ }^{8}$ found epithelial proliferation and subsequent exfoliation of the

Received for publication June 24, 1971. implanted acrylic teeth. Similar results were obtained by Tobin-White, ${ }^{9}$ who placed acrylic teeth into sockets in which fluid acrylic resin had been introduced before positioning the implants. These conflicting reports indicated a necessity for further investigation. We thought that the histopathologic condition of the periodontium in relation to the acrylic restoration must be delineated clearly.

The present study is a histological examination of the periodontium of replanted teeth that had an acrylic restoration in the middle third of their roots. The study was done from three days to six months after grafting. With this model, observations of the periodontal tissue reaction around cementum and the acrylic restoration could be compared.

\section{Materials and Methods}

Nine healthy male thesus monkeys (Macaca mulatta) were used for this study. All the monkeys were adults and were approximately the same size and weight. A step by step sequence of the methods used was reported recently.10 Briefly, after extraction, the left central maxillary incisors were treated endodontically with zinc oxideeugenol paste and gutta-percha points, and a cavity was prepared in the distal aspect of the middle third of the roots. The prepared cavity was filled with a cold-curing acrylic resin* and after four minutes setting time, the tooth was replanted. For stabilization, the replants were splinted by cementing a common metal inlay into previously prepared cavities of the central incisors. After surgery, the monkeys were given $100 \mathrm{mg}$

* Sevriton, Amalgamated Dental Trade Dist., Ltd., London, Eng. 


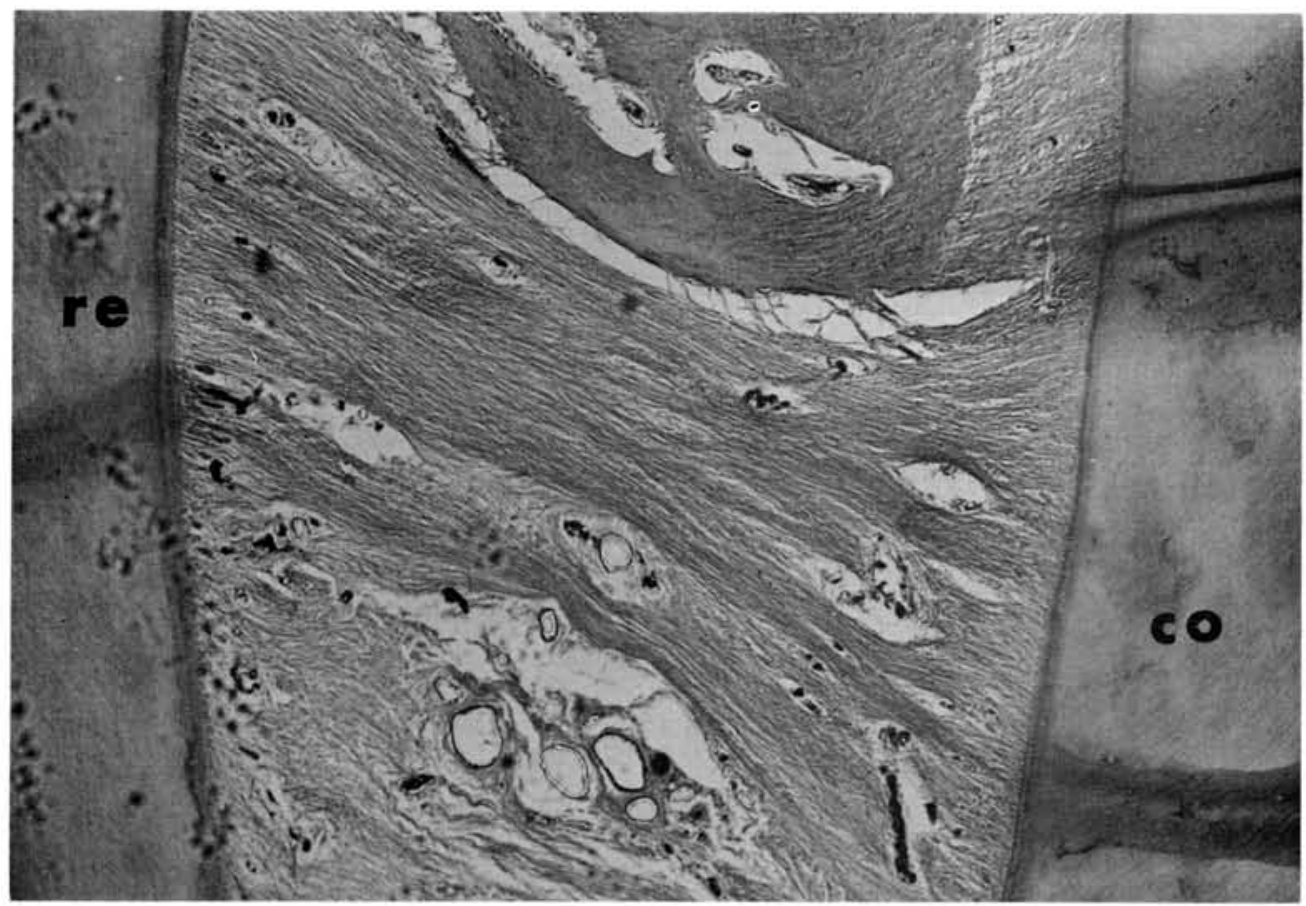

Fig 1.-Twenty one days after tooth replantation. Dense band of transseptal periodontal fibers extends from cementum of replanted tooth ( $\mathrm{re}$ ) to cementum of control untreated tooth (co) over crest of alveolar bone septum (H\&E stain; orig mag $\times 45$, reproduced at $78 \%$ ).

oxytetracycline* dissolved in 16 ounces of water daily and were maintained on a soft diet for the first week. The monkeys were killed postoperatively at $3,6,21$, and 30 days, and at three, four, and six months. The involved teeth with surrounding bone and soft tissue were excised in block sections. These sections were fixed in $10 \%$ buffered Formalin solution, and were decalcified in either formic or nitric acid. Acrylic restorations were dissolved in chloroform for four hours. Serial sections of the decalcified, paraffin-embedded tissues were sectioned in the mesial-distal direction, and stained with hematoxylin and eosin (H\&E) and Mallory's periodic acid-Schiff (PAS) stain, for histological examination.

\section{Results}

Histological sections of the three day postoperative specimen disclosed a broad zone of fibrin clot, which was undergoing organization. Despite the lack of epithelial reattach-

* Cosa Terramycin, Pfizer \& Co., Inc., New York, ment and the intense leukocytic infiltration, the original connective tissue outline was preserved without noticeable sloughing. By six days, the crevicular epithelium was reattached at the cementoenamel junction, and further repair was observed by proliferation of epithelial cells, which quantitatively restored the thickness of the tissue in that region. The blood clot in this specimen was replaced partially by loose fibrillar tissue, and at the periphery of the clot there was evidence of vascular proliferation. Lymphocytic and histocytic inflammatory cells became prominent along the replanted root. The collagen fibers of the periodontal membrane demonstrated increased cellularity, and a definite tendency toward orientation.

In the middle third of the root, adjacent to the acrylic obturator, a trace of a thin zone of parallel collagen fibers with interspersed leukocytes was seen. Between this zone and the interdental septum of the alveolar bone, the connective tissue seemed slightly edematous and periodontal fibers appeared somewhat disoriented. Healing in the 21-day specimen was advanced considerably 
over that observed in the six-day specimen. The subgingival connective tissue was infiltrated moderately with chronic inflammatory cells, and a dense band of transseptal periodontal fibers extended from the cementum of one incisor to the cementum of the adjacent incisor over the crest of the interdental septum of alveolar bone (Fig 1 ). At the acrylic site there was a notable zone of moderate round cell infiltration, fibrosis, and fatty tissue, as well as hyalin, degeneration. Coarse connective tissue fibers were aligned parallel to the acrylic cavity. When the apical portion of the root was scanned, fibroblastic and osteoblastic activity was evident, and cemental resorption and dentoalveolar ankylosis were a common finding.

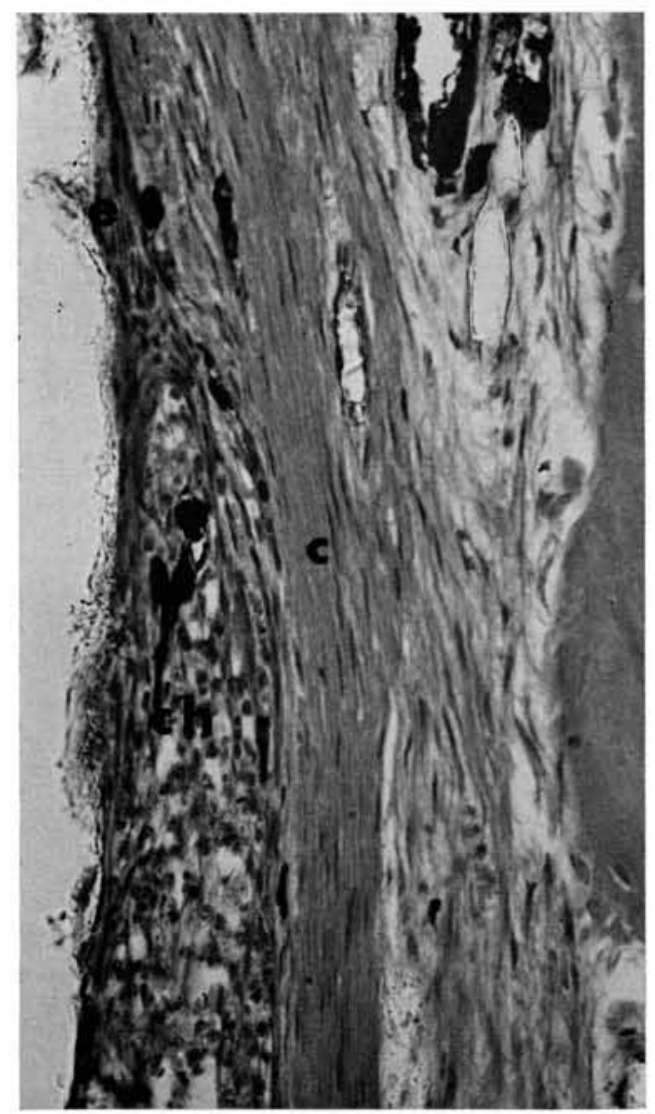

FIG 2.-Acrylic site of a 30-day replanted tooth. Polymer elicited epithelial proliferation $(e)$, fibrous encapsulation (c), and chronic inflammation $(c h)$ (H\&E stain; orig mag $\times 250$, reproduced at $67 \%$ ).

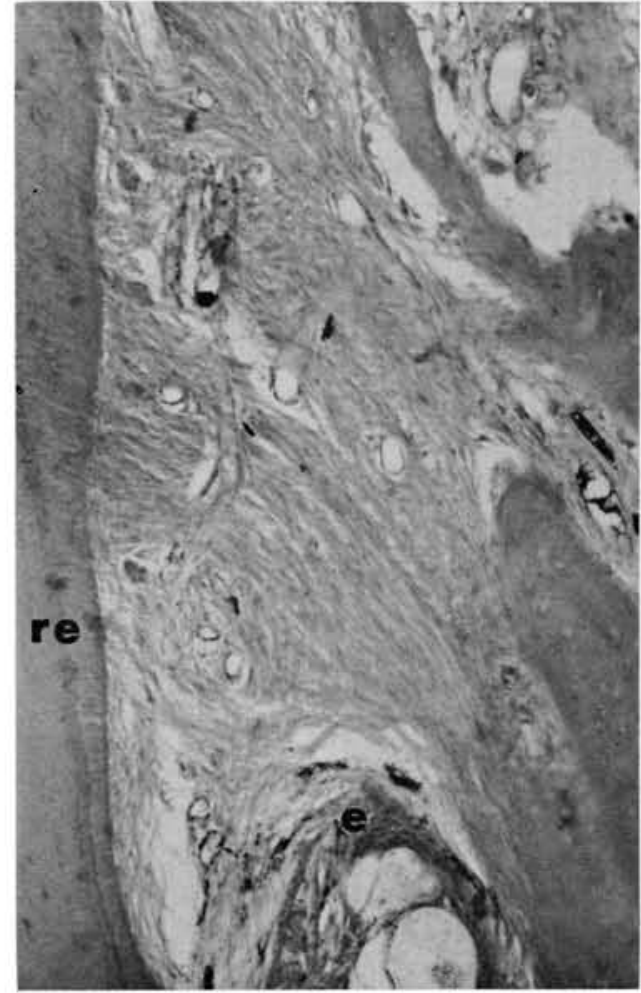

FIg 3.-Area between cervical third and acrylic third of root of a 30-day specimen. Note fibrous components of encapsulated zone attaching to root cementum. re, Replanted tooth; $e$, epithelial proliferation (H\&E stain; orig mag $\times 250$, reproduced at $56 \%$ ).

Three specimens were available for a 30 day postoperative evaluation. In every instance, the cervical third of the root showed a decrease in the cellularity of the periodontal membrane. Occasionally, epithelial rests of Malassez and pools of fibrillar material without definite arrangements were noted. In all three specimens, tissue elements adjacent to the acrylic cavity showed the following features: (1) An epithelial proliferation extended over the whole acrylic wall (Fig 2); however, this epithelial proliferation was not connected with the crevicular epithelium. This epithelial proliferation appeared to form a protective barrier between the acrylic obturator and the adjacent connective tissue fibers. (2) In the periodontal space and covering the epithelial proliferation, the acrylic restoration also elicited the formation of a fibrous encapsulation. 
The fibers forming this encapsulated zone were parallel to the epithelial proliferation as well as to the acrylic cavity, which denotes a nonfunctional orientation. The fibrous components of the encapsulated zone were attached to the cementum root surface (Fig 3). (3) A chronic inflammatory reaction was present in the epithelial proliferation layer and in the fibrous encapsulation layer. There was a moderate number of foreign body cells, macrophages, lymphocytes, and polymorphonuclear leucocytes (Fig 2). (4) A notable decrease in osteoblastic activity at the mesial margins of the interdental septums and a somewhat granular appearance of the bone was observed. In addition, the amount of osteoid was decreased locally. In the apical third of the root, the specimens showed dentoalveolar ankylosis with a decrease in fibroblastic activity.

Three months after surgery, the replanted tooth showed an intense, progressive, osteoblastic activity around the apical half of the root. The periodontal space was interrupted by sporadic regions of bony ankylosis associated with cemental resorption and cemental deposition. However, at the acrylic site a rapid fibroblastic proliferation was noted in the fibrous capsule; it also appeared to infiltrate the adjacent bone and dentin. Details of this nonmalignant lesion were reported recently. ${ }^{10}$

The four- and six-month specimens had a normal periodontal membrane over the major portion of the replanted root surfaces; however, there was invariably induction of epithelial proliferation, fibrous encapsulation, chronic inflammation, and osteoblastic activity at the acrylic site. In contrast to the earlier replants, the four- and six-month specimens did not show dentoalveolar ankylosis, and regions of cemental resorption had been repaired by extensive deposits of new cementum.

\section{Discussion}

There seems to be no disagreement as to the necessity of replacing the pulp with a proper filling before tooth replantation, ${ }^{11-13}$ as well as to replanting teeth with the original periodontal fibers attached. ${ }^{14-16}$ Löe and Waerhaug 17 conducted long-term experiments in which they intentionally replanted teeth in dogs and monkeys; their studies showed that it is possible for a normal perio- dontal membrane to become reestablished after replantation. In their work, dentoalveolar ankylosis was not observed; and, without exception, connective tissue filled the space between the transplanted root and the alveolar bone.

In the present study half of the tooth replants showed dentoalveolar ankylosis, whereas the other half did not show dentoalveolar ankylosis. The cause for these different responses could not be determined. In the present study, such factors as exodontia, as well as overmanipulation during root canal therapy and acrylic cavity preparation, may account for the response of the teeth that resulted in dentoalveolar ankylosis. Hammer ${ }^{18}$ suggested that the centers of resorption and apposition in replanted teeth would lend themselves to ankylosis. In his opinion, resorption starts where the periodontal membrane is damaged during tooth extraction, and it may be that these regions give rise to ankylosis. Tooth replants demonstrating an absence of ankylosis had functional periodontal fibers supporting the tooth and attaching to both the alveolar bone and cementum. In addition, small regions of previous root resorption had been repaired by new cementum.

Previously, Hodosh and associates ${ }^{2-4}$ used exact replicas of natural teeth fabricated of heat-cured acrylic resin, and reported that the fibers in the periodontal membrane surrounding the acrylic tooth implant tended to run in a more vertical orientation; that these fibers inserted directly into the acrylic resin; and, that the surrounding alveolar bone had osteoblastic activity along the periodontal membrane surface. Contrary to these findings, the present study revealed that the acrylic obturator elicited epithelial proliferation, fibrous encapsulation, chronic inflammation, and a decrease in osteoblastic activity of the adjacent alveolar bone septums. The factors responsible for these reactions in our study are still unclear. Since we used cold-cured acrylic resin, which is polymerized at room temperature, there could be a possibility of incomplete polymerization that left monomers present which may have caused the observed tissue responses. However, Waerhaug and Löe ${ }^{19}$ concluded that there was no basic difference in the tissue reaction to cold-cured and heat-cured acrylic resins. 
Our findings are consistent with, and help to explain, earlier reports of acrylic tooth implant failures as reported by Waerhaug and Zander, ${ }^{6}$ Narang and Wells, ${ }^{7}$ Iwaschenko, ${ }^{8}$ and Tobin-White, ${ }^{9}$ among others. These investigators explored acrylic tooth implants as a possible substitute for natural teeth and found that some of their tooth implants showed gingival inflammation, alveolar bone loss, epithelial proliferation, or exfoliated teeth. It should be noted that, in Cserepfalvi's opinion, ${ }^{20}$ the experiments with artificial implants are certain to lead to failure because they are contrary to the biologic principle that no living tissue can survive, without ill effect, any long lasting pressure that exceeds the capillary pressure. Furthermore, Orban ${ }^{21}$ has suggested that reattachment of periodontal fibers can "only be a reattachment of connective tissue ... when, connective tissue comes into contact with cementum root surface."

More important, the current debate is focused on reports of successful acrylic tooth implants in human beings, ${ }^{2-4}$ in spite of the evidence which contraindicates the use of acrylic implants in man. ${ }^{22-2 \bar{s}}$ Experimental work with rats by Oppenheimer and associates $^{22}$ has shown that acrylic resin embedded subcutaneously for approximately one year in film or sheet form induced sarcomas in significant numbers, up to $50 \%$. They stated that the chemical or physicochemical interaction between the acrylic resin and the tissue is the chief carcinogenic factor. Stinson ${ }^{23}$ reported that malignant changes occurred in the fibrous hyaline capsule around large and medium sized acrylic disks when used in rats. Hueper ${ }^{24}$ observed a difference in carcinogenecity between various water-soluble and waterinsoluble polymers. However, it should be noted that although the propensity of rodents to form short-term sarcomas, causes one to be alert to the danger of acrylic resins, it must not lead one to expect similar short-term results in man. Brown ${ }^{25}$ has suggested that if it takes one year to develop a sarcoma in a rat, this time could be extrapolated in man to 15 or 20 years. Therefore, the advisability of using acrylic tooth implants in man is questionable until longterm animal investigation has been completed.

The search for materials to repair or replace human or animal tissues has been provocative, often discouraging, and never without debate. It is clear why dental investigators have sought a material like acrylic resin to replace natural teeth. The appeal of acrylic resins is apparent because such polymers are available in unlimited quantities, and they are relatively inexpensive to produce. Further, the acrylic tooth may be made in the desired size, shape, and color. However, to date, there is serious doubt as to whether acrylic tooth implants have survived in toto. ${ }^{6-9}$

\section{Conclusions}

The purpose of the present study was to examine the periodontium of replanted teeth that had a cold-cured acrylic obturator in their roots. Periodontal tissue reaction around root cementum and the acrylic restoration were compared.

The study showed that it is possible for a normal periodontal membrane to become reestablished after tooth replantation. However, the acrylic restoration elicited epithelial proliferation, fibrous encapsulation, chronic inflammation, and alveolar bone loss. These findings are in accord, and help to explain, earlier reports of acrylic tooth implant failures that included gingival inflammation, epithelial proliferation, alveolar bone loss, and tooth exfoliation.

Since previous reports contraindicate the use of acrylic implants in man, we question the advisability of using them in man until long-term animal investigation has been completed.

\section{References}

1. Flohr, W.: L'Implantation de Resine au Niveau de la Face et des Maxillaries Resultats Cliniques et Histologiques, Rev Stomatol [Paris], 54:113, 1953.

2. Hodosh, M.; Montagna, W.; Povar, M.; and SHKLAR, G.: Implants of Acrylic Teeth in Human Beings and Experimental Animals, Oral Surg 18:569-579, 1964.

3. Hodosh, M.; Povar, M.; and Shklar, G.: Periodontal Fiber Attachment to the Plastic Tooth Implant, J Periodontol 39:5-7, 1968.

4. Hodosh, M.; Povar, M.; and ShKLaR, G.: The Dental Polymer Implant Concept, $J$ Prosthet Dent 22:371-380, 1969.

5. Brown, B.H.; NefF, P.A.; and Tylenda, A.: Acrylic Resin Tooth Implants in Rhesus Monkeys. A Preliminary Report, J Prosthet Dent 22:367-370, 1969. 
6. Waerhaug, J., and Zander, H.: Implantation of Acrylic Roots in Tooth Sockets, Oral Surg 9:46-54, 1956.

7. Narang, R., and Wells, H.: Decalcified Allogenic Bone Enhances the Successful Maintenance of Implanted Acrylic Teeth, abstracted, IADR Program and Abstracts of Papers, No. 259, 1971.

8. Iwaschenko, G.M.: On the Possibility of Implanting Acrylic Teeth and Roots, Stomatologiia (Mosk) 36:52-53, 1957.

9. ToBin-White, A.: Implantation of Acrylic Teeth in the Jaws, Int Dent J 8:15, 1958.

10. Castelli, W.A.; Nasjleti, C.E.; Huelke, D.F.; and Diaz-Perez, R.: Revascularization of the Periodontium After Tooth Grafting in Monkeys, $J$ Dent Res 50:414421, 1971.

11. Knight, M.K.; Gans, B.J.; and Calandra, J.C.: The Effect of Root Canal Therapy on Replanted Teeth of Dogs. A Gross, Roentgenographic, and Histologic Study, Oral Surg 18:227-242, 1964.

12. Rothschild, D.L.; Goodman, A.A.; and BLAKEY, K.R.: A Histologic Study of Replanted and Transplanted Endodontically and Nonendodontically Treated Teeth in Dogs, Oral Surg 28:871-876, 1969.

13. DEEB, E.: Intentional Replantation of Endodontically Treated Teeth, in Transactions of the Fourth International Conference on Endodontics, University of Pennsylvania, 1968, pp 147-157.

14. BöDEcker, C.F., and Lefkowitz, W.: Replantation of Teeth, Dental Items 57:675$692,1935$.

15. Hammer, H.: Der Histologische Vorgang bei der Zahn-Replantation Dtsch Kieferchir 1:115-136, 1934.
16. Andreasen, J.O., and HJørting-Hansen, E.: Replantation of Teeth. II. Histological Study of 22 Replanted Anterior Teeth in Human, Acta Odontol Scand 24:287-306, 1966.

17. LöE, H., and WaErhaug, J.: Experimental Replantation of Teeth in Dogs and Monkeys, Arch Oral Biol 3:176-184, 1961.

18. HAMMER, H.: Der Histologische Vorgang bei der Zahn-Replantation Nach Vernichtung der Wurzelhaut, Dtsch Zahn Mund Kieferheilkd, 4:179-187, 1937.

19. Waerhaug, J., and LöE, H.: Tissue Reaction to Self-Curing Acrylic Resin Implants, Dent Pract Dent Res 8:234-240, 1958.

20. Cserepfalvi, M.: Transplantation of Teeth in the Human, in PeEr, L.A. (ed): Transplantation of Tissues, vol. 2, Baltimore: Williams and Wilkins, 1959, p 301.

21. ORBAN, B.: Pocket Elimination or Reattachment, NY State Dent J 14:227, 1948.

22. OPPENHEIMER, B.S.; OPPENHEIMER, E.T.; Stout, A.P., Willhite, M.; and DanishefSKY, I.: The Latent Period in Carcinogenesis by Plastics in Rats and Its Relation to the Presarcomatous Stage, Cancer 11:204-213, 1958.

23. Stinson, N.E.: The Tissue Reaction Induced in Rats and Guinea Pigs by Polymethylmethacrylate (Acrylic) and Stainless Steel, Br J Exp Path 45:21-29, 1964.

24. Hueper, W.C.: Carcinogenetic Studies on Water Soluble and Insoluble Macromolecules, Arch Path (Chicago) 67:587-617, 1959.

25. Brown, D.E.: Tissue Reaction to Plastic and Metal Implants, Arch Otolaryngol 88: 283-287, 1968. 